\title{
RANCANG BANGUN APLIKASI ANDROID INFORMASI RUTE BUS MAYASARI BAKTI DENGAN ALGORITMA KNUTH- MORRIS-PRATT
}

\author{
Fransiscus Xaverius Syahasta A.T. ${ }^{1}$ \\ hastatan@gmail.com
}

\author{
Seng Hansun ${ }^{2}$ \\ hansun@umn.ac.id
}

\begin{abstract}
This research is about design and development of information application of Mayasari Bakti buses' route for smartphones based on Android operating system. To search for the expected bus, this application implements Knuth-Morris-Pratt Algorithm. The application was tested on 41 respondents and the result is very useful to search for one until two buses which can take the passengers from an origin to destination location which have been selected before, and show it up on a map.
\end{abstract}

Keywords: Android, Knuth-Morris-Pratt, Mayasari Bakti, Pattern Matching.

\section{Pendahuluan}

D.K.I. Jakarta merupakan kota terbesar sekaligus ibukota bagi negara Indonesia. Menurut Pemendagri nomor 66 tahun 2011, kota yang berlambangkan tugu monas ini mempunyai luas wilayah daratan $664,01 \mathrm{~km}^{2}$ dengan jumlah penduduk 9.809 .857 jiwa, dan terus bertambah seiring berjalannya waktu.

Pertambahan jumlah penduduk menuntut jasa transportasi yang dapat menjangkau secara keseluruhan. Namun pada kenyataannya (Agus, 2010), ketersediaan TransJakarta yang dikelola pemerintah belum mampu mengimbanginya, sehingga jasa angkutan umum lama, seperti bus Mayasari Bakti, masih perlu turun tangan untuk menutupi kekurangan kapasitas dan jangkauan TransJakarta.

Sebelumnya telah ada penelitian oleh Fuaduddin dkk. (2012) dengan judul Aplikasi Informasi Trayek Angkutan Umum Berbasis Mobile dengan Penerapan Pencocokan String Algoritma Brute Force, yang dilatar belakangi oleh kesulitan masyarakat dalam mencari informasi mengenai rute suatu bus.

Berbeda dengan penelitian oleh Fuaduddin dkk. (2012) yang memerlukan satu lokasi sebagai input dan pencariannya menggunakan algoritma Brute Force, penelitian ini memerlukan dua lokasi sebagai input, yaitu satu lokasi sebagai lokasi asal dan satu lagi sebagai lokasi tujuan, dimana pencarian bus menggunakan algoritma Knuth-Morris-Pratt dan lokasi-lokasi pada pilihan rute yang ada dapat ditampilkan pada peta yang menggunakan Google Maps API.

Algoritma Knuth-Morris-Pratt dipilih karena keefisienannya dalam melakukan pencarian, informasi yang didapatkan dari pencarian yang telah dilakukan disimpan dan digunakan untuk menentukan jumlah lompatan karakter berikutnya, sehingga maksimum terjadinya pencocokan pada karakter yang sama hanya sebanyak dua kali.

Melihat perkembangan teknologi yang ada, aplikasi hasil penelitian ini ditujukan kepada ponsel yang bersistem operasi Android. Sistem operasi Android dipilih karena merupakan sistem operasi yang terbuka dan menjamur pada kebanyakan ponsel pintar, baik besutan produsen lokal maupun luar.

\footnotetext{
${ }^{1}$ Program Studi Teknik Informatika, Fakultas Teknologi Informasi dan Komunikasi, Universitas Multimedia Nusantara

${ }^{2}$ Program Studi Teknik Informatika, Fakultas Teknologi Informasi dan Komunikasi, Universitas Multimedia Nusantara
} 


\section{Landasan Teori}

\subsection{Android}

Menurut Bhawiyuga dkk. (2011), Android merupakan sistem operasi untuk ponsel berbasis Linux yang ber-platform terbuka bagi para pengembang guna menciptakan aplikasi yang dirancangnya. Sistem Android pada dasarnya berisikan tumpukan dari beberapa lapisan agar perangkat keras dapat berinteraksi dengan pengguna.

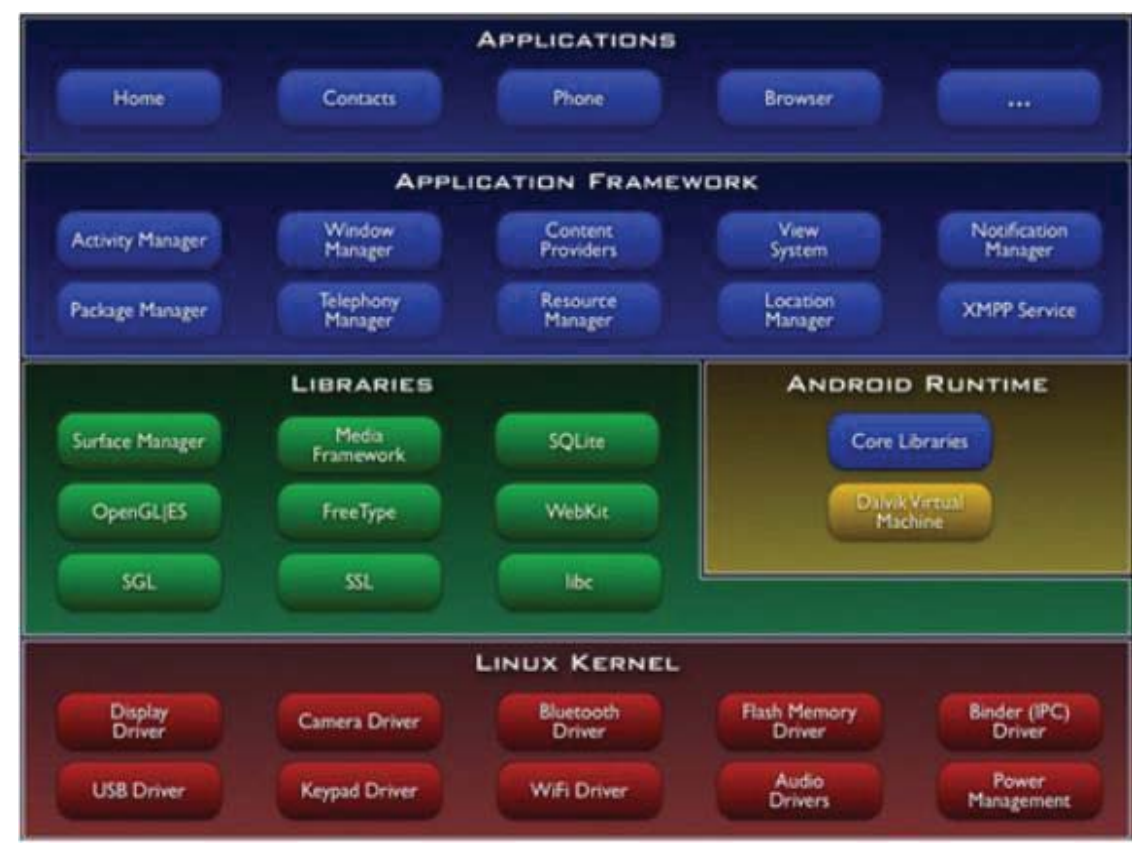

Gambar 1. Lapisan sistem operasi Android (Bhawiyuga dkk., 2011)

\subsection{Eclipse IDE}

Menurut Lindung (2012), Eclipse merupakan sebuah Integrated Development Environment (IDE) untuk pengembangan perangkat lunak dan dapat dijalankan di semua platform. Adapun sifat-sifat dari Eclipse yaitu multi-platform, multi-language, dan multi-role. Eclipse bisa didapatkan secara gratis dan bersifat open-source, serta dapat dikembangkan dengan komponen yang dinamakan plug-in oleh penggunanya.

\subsection{Android SDK}

Website resmi developer Android (http://developer.android.com) menjelaskan bahwa Android SDK merupakan penyedia API libraries dan alat pengembang yang diperlukan untuk membangun, menguji, dan menelusuri aplikasi Android menggunakan bahasa pemrograman Java yang dapat digunakan para pengembang secara gratis.

\subsection{Bus Mayasari Bakti}

Zulkifli (2014) mengatakan bahwa perusahaan bus Mayasari Bakti berdiri pada tahun 1964. Perusahaan yang berkantorkan di Ciracas, Jakarta Timur ini merupakan salah satu penyedia jasa dalam bidang transportasi yang beroperasi di Jabodetabek dengan rute terbanyak dan dapat dikategorikan sebagai bus kota, karena memiliki lebih dari 50 trayek dengan kategori patas AC, patas non-AC, dan reguler. Namun ada beberapa rute yang harus dihapus karena sudah dijangkau oleh TransJakarta.

\subsection{Algoritma Knuth-Morris-Pratt}

Berbeda dengan algoritma Brute Force (Yusup, 2010), Algoritma Knuth-Morris-Pratt (KMP) ini memelihara informasi yang digunakan untuk melakukan jumlah pergeseran agar pergeseran yang dilakukan lebih jauh, tidak hanya bergeser sebanyak satu karakter. Untuk kompleksitasnya, algoritma ini menemukan semua kemunculan dari pattern dengan panjang $\mathrm{n}$ di dalam teks dengan panjang $\mathrm{m}$ dengan kompleksitas waktu $\mathrm{O}(\mathrm{m}+\mathrm{n})$. Algoritma ini hanya 
membutuhkan $\mathrm{O}(\mathrm{n})$ ruang dari memory internal jika teks dibaca dari file eksternal. Semua besaran $\mathrm{O}$ tersebut tidak tergantung pada besarnya ruang alfabet.

Secara sistematis, beberapa langkah yang dilakukan algoritma Knuth-Morris-Pratt pada saat mencocokkan string sebagai berikut:

1) Algoritma Knuth-Morris-Pratt mulai mencocokkan pola pada awal teks.

2) Dari kiri ke kanan, algoritma ini akan mencocokkan satu per-satu karakter pola dengan karakter teks yang sesuai, sampai salah satu kondisi berikut terpenuhi:

a) Karakter pada pola dan teks yang dibandingkan tidak cocok.

b) Semua karakter di pola cocok, maka algoritma akan memberitahukan penemuan di posisi yang sesuai tersebut.

Algoritma kemudian menggeser pola berdasarkan tabel, lalu mengulangi langkah kedua sampai pola yang berada di ujung teks.

\subsection{Google Maps API}

Menurut Elian dkk. (2012), Google Maps API merupakan javasript library hasil pengembangan Google Maps, yaitu layanan aplikasi dan teknologi pemetaan berbasis web oleh Google yang bersifat gratis. Dengan library yang berbentuk javascript ini, dimungkinkan untuk memodifikasi peta yang ada di Google Maps sesuai dengan kebutuhan pengembangan.

\subsection{Skala Likert}

Skala Likert ditemukan pada tahun 1932 oleh Rensis Likert dalam laporannya yang menjelaskan kegunaan skala Likert. Harahap (2011) mengemukakan bahwa skala ini merupakan suatu skala psikometrik yang banyak digunakan pada kuesioner maupun survei dengan menggunakan beberapa tingkatan skala, misalnya lima tingkatan dengan skala: Sangat Setuju, Setuju, Netral, Tidak Setuju, dan Sangat Tidak Setuju, dengan masing-masing bobot untuk setiap tingkatnya. Bobot yang dimiliki pada setiap tingkatan berguna dalam melakukan analisis dan penarikan kesimpulan.

Kepuasan menurut Kotler (2003), merupakan suatu perasaan, baik senang maupun kecewa, yang timbul setelah membandingkan bayangan dan harapannya dengan hasil kinerja suatu produk maupun jasa. Ives dkk. (1983) berpendapat bahwa kepuasan pengguna yaitu pengukuran seberapa jauh informasi yang disediakan untuk pengguna dapat memenuhi informasi yang diperlukannya.

\section{Metodologi Penelitian dan Perancangan Aplikasi \\ 3.1 Metodologi Penelitian}

Pada pelaksanaan, metodologi penelitian yang digunakan, yaitu dengan tahapan seperti berikut:

1) Studi pustaka

Studi pustaka merupakan tahapan pembelajaran terhadap sumber-sumber yang dapat dijadikan acuan dalam penelitian, seperti literatur mengenai informasi bus dan rute bus Mayasari Bakti (Dinas Komunikasi, Informatika, dan Kehumasan Pemprov DKI Jakarta, tt.; Indriany, tt.), Google Maps API (Emmanuel dan Salim, 2013; Matthew, 2013; Google Developers, 2014; Naufal, 2014), dan Knuth-Morris-Pratt (Yusup, 2010; Andika, 2012).

2) Perancangan dan pengembangan aplikasi

Pada tahapan ini, analisis terhadap prosedur yang sesuai untuk penelitian dilakukan agar aplikasi hasil dari penelitian ini dapat mencapai tujuan.

3) Ujicoba aplikasi

Tahapan ujicoba dilakukan selagi aplikasi dikembangkan, hal ini dimaksudkan supaya perintah-perintah yang dimasukkan dapat dipastikan berjalan sebagaimana mestinya, dan apabila ada kesalahan tidak akan menumpuk hingga sulit untuk dideteksi.

4) Pengumpulan sampel dan validasi data

Dalam tahapan ini dibutuhkan sejumlah responden untuk mencoba aplikasi yang telah dibuat. Responden yang telah mencoba aplikasi kemudian diberikan sejumlah pertanyaan dalam bentuk kuesioner guna mendapatkan jawaban yang akan dijadikan sampel data. 
Aplikasi juga diperlihatkan dan diujicobakan kepada pihak Mayasari Bakti, sekaligus melakukan validasi rute.

\section{5) Analisis sampel data}

Sampel data yang telah dikumpulkan dari para responden kemudian dianalisis untuk mengetahui bahwa algoritma Knuth- Morris-Pratt beserta fitur pelengkapnya dapat berfungsi dengan baik dalam pencarian bus sesuai dengan input responden.

6) Penulisan laporan

Dokumentasi yang ada pada setiap tahap, hingga penarikan kesimpulan dari hasil analisis data, kemudian disusun untuk dijadikan sebuah laporan penelitian.

\subsection{Perancangan Aplikasi}

Melalui Gambar 2 dapat diketahui jalannya aplikasi yang bermula pada halaman Loading hingga aplikasi selesai.

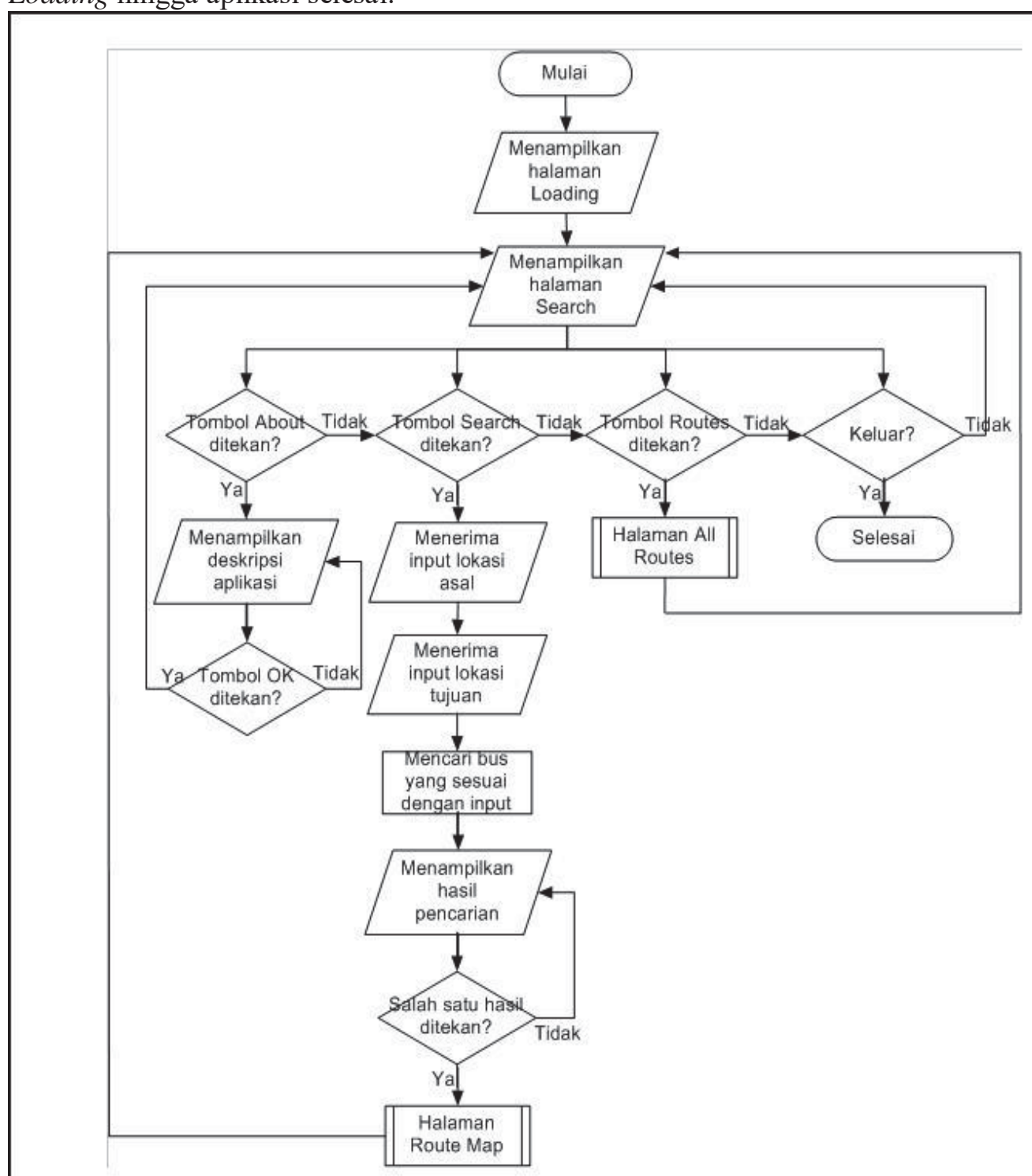

Gambar 2. Diagram alir aplikasi

Gambar 3 merupakan diagram alir dari halaman All Routes. Pada halaman ini semua pilihan rute akan ditampilkan dan akan menunjukkan lokasi-lokasinya ketika user menekan salah satu pilihan rute. Sama seperti halaman lainnya, terkecuali halaman Loading, disediakan pula tombol About untuk memberikan deskripsi mengenai aplikasi, baik kegunaan aplikasi maupun cara penggunaan aplikasi. 


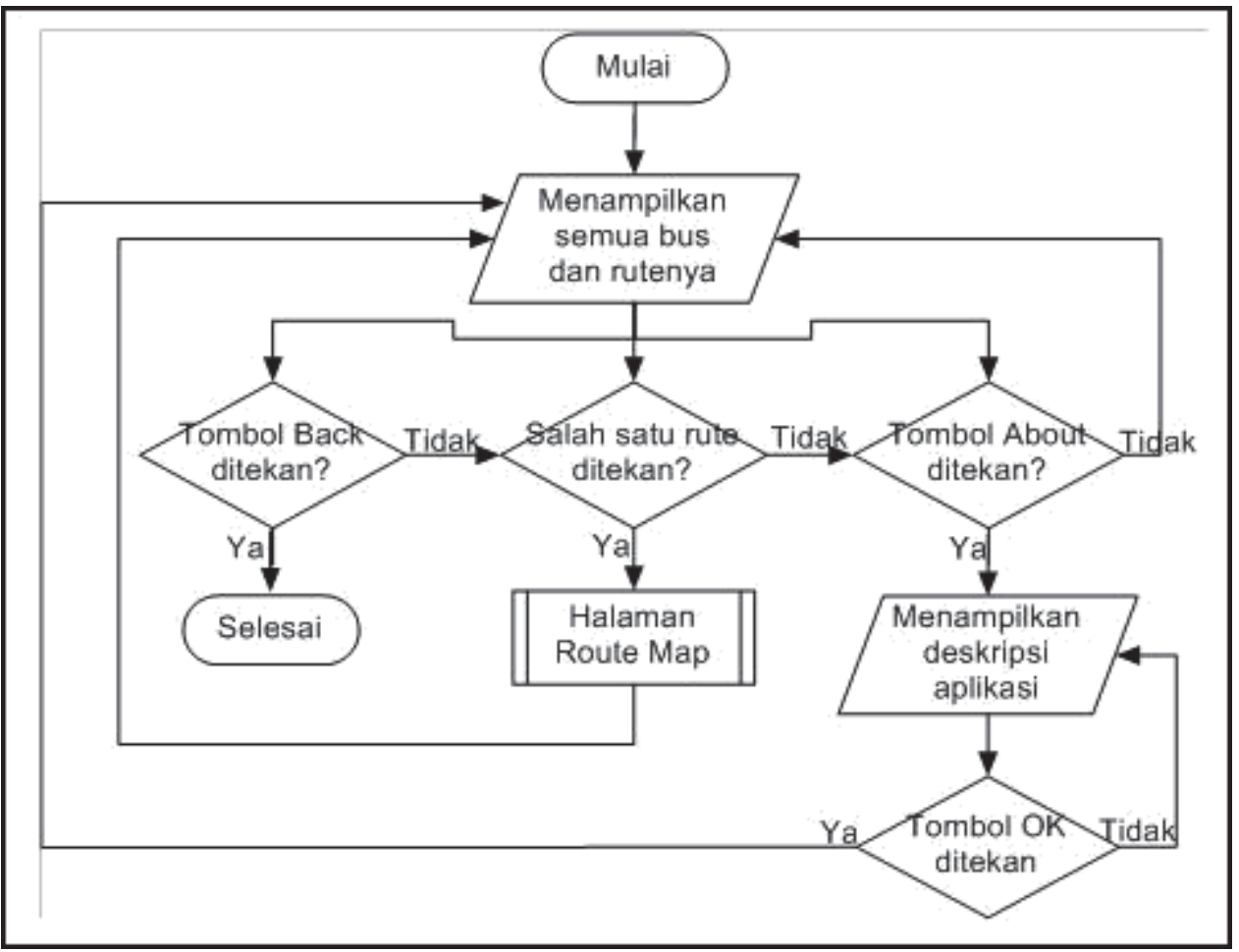

Gambar 3. Diagram alir halaman All Routes

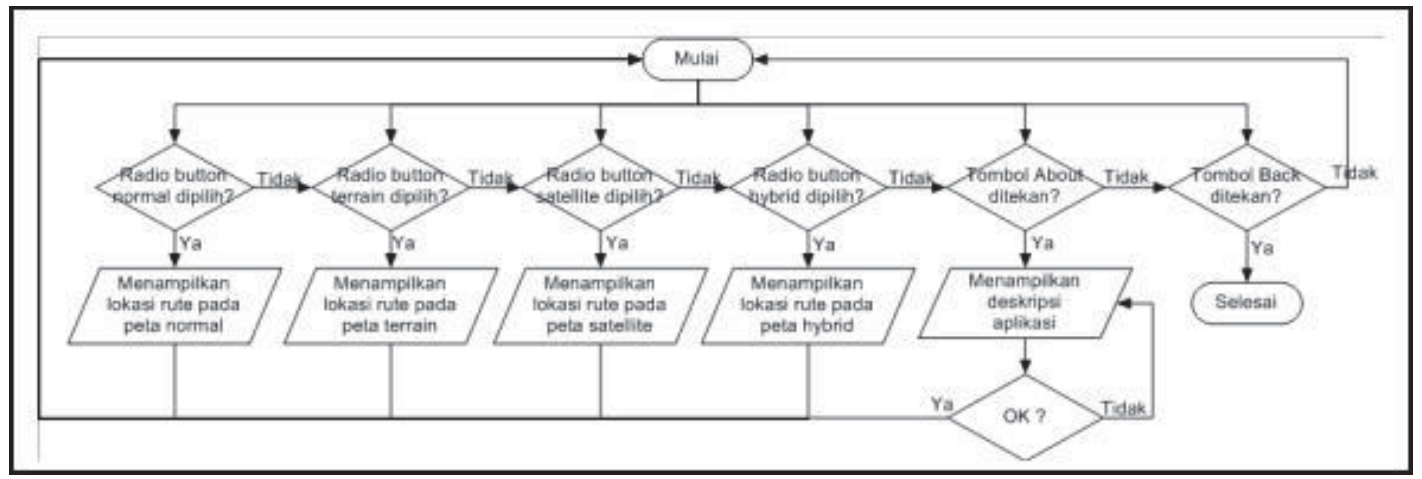

Gambar 4. Diagram alir halaman Route Map

Halaman Route Map yang diagram alirnya diperlihatkan pada Gambar 4 berfungsi untuk menampilkan lokasi-lokasi rute pada peta, baik dalam model peta normal, terrain, satellite, dan hybrid. Untuk penyimpanan data koordinat dan busnya, aplikasi ini menggunakan file system, terdapat dua file system, yaitu Rute.txt dan Latlng.txt.

Pencarian bus pada aplikasi ini dilakukan dengan mencari lokasi asal dan lokasi tujuan yang dimasukkan oleh user, dengan menggunakan algoritma Knuth-Morris-Pratt. Diagram alir dari algoritma Knuth-Morris-Pratt (KMP) dapat dilihat pada Gambar 5. 


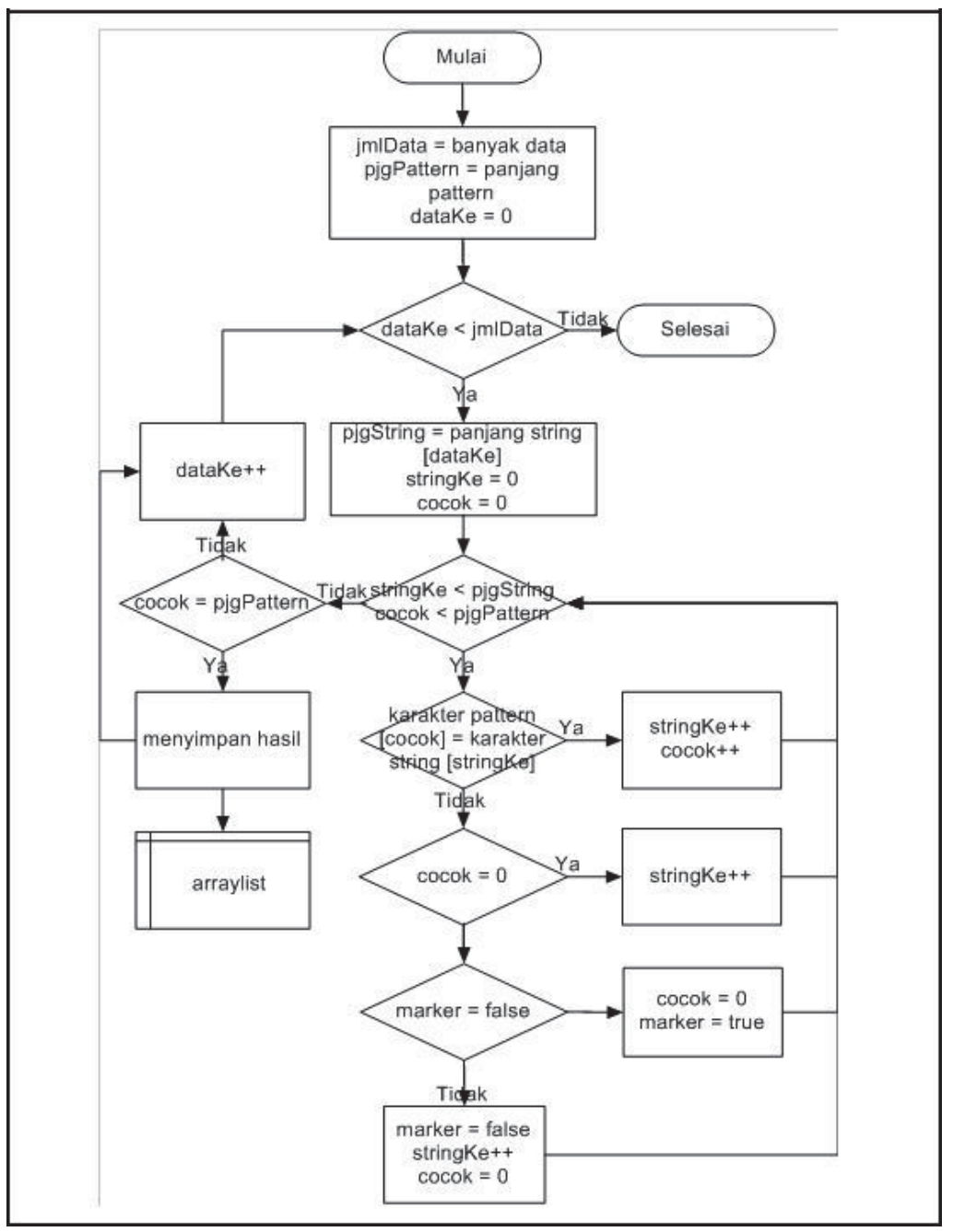

Gambar 5. Diagram alir algoritma KMP

\section{Implementasi dan Ujicoba}

\subsection{Hasil Implementasi}

Aplikasi informasi rute bus Mayasari Bakti ini diujicobakan pada Samsung Galaxy S4 GT-i9500.
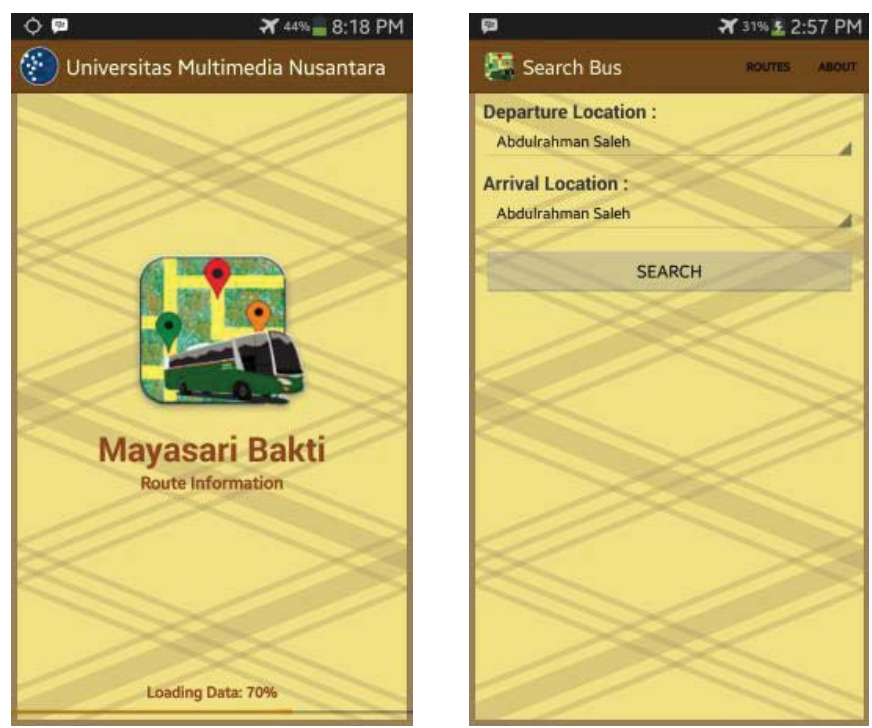

Gambar 6. Tampilan akhir halaman Loading dan Search Bus 
Gambar 6 menunjukkan tampilan akhir halaman Loading dan tampilan akhir halaman Search Bus yang di-capture saat pengujicobaan.

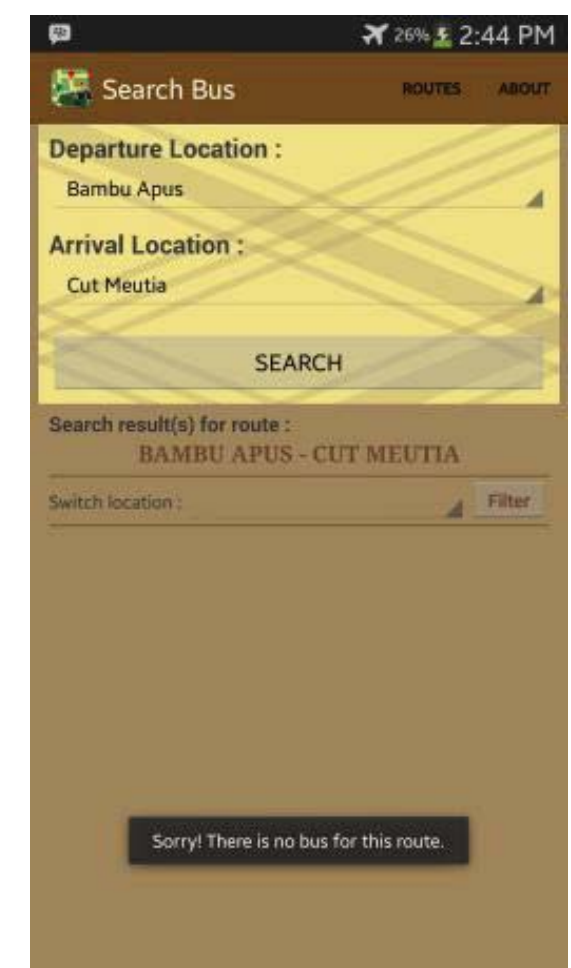

Gambar 7. Tampilan ketika tidak ada hasil

Pencarian yang dilakukan pada aplikasi ini belum tentu membuahkan hasil, karena pencarian masih terbatas pada cakupan bus, yaitu hanya dapat mencakup maksimal dua bus untuk suatu rute perjalanan. Ketika suatu perjalanan mempunyai banyak hasil, tersedia fitur filter untuk menyaring hasil pencarian berdasarkan lokasi perpindahan dari bus pertama ke bus kedua.

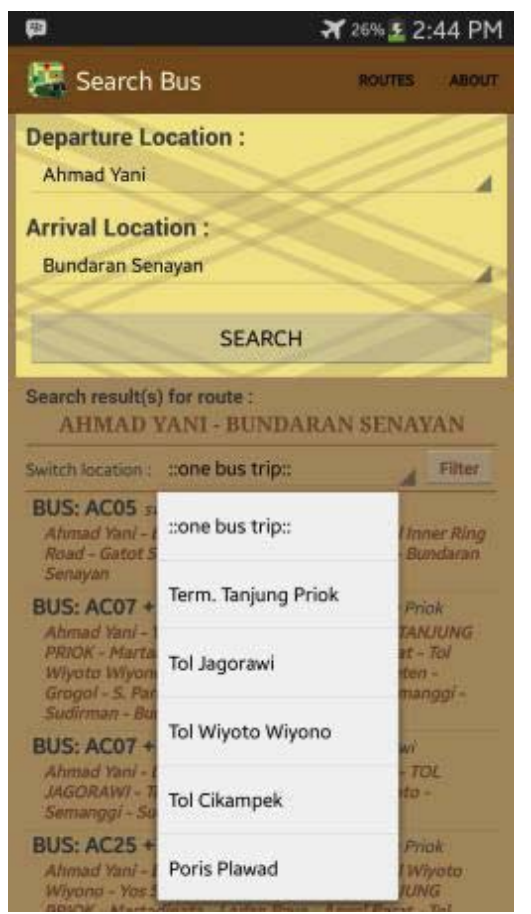

Gambar 8. Tampilan filter hasil pencarian 
Ketika salah satu pilihan rute, baik pada hasil pencarian maupun daftar semua rute dipilih, maka halaman Route Map akan terbuka seperti pada Gambar 9, dan menampilkan peta pada model normal. Model normal akan menampilkan peta pada umumnya yang menampilkan garis-garis untuk menggambarkan jalan, sungai dan keterangan lain seperti nama kota maupun area kota. Ketika penanda lokasi ditekan, nama lokasi dari penanda tersebut akan ditampilkan.

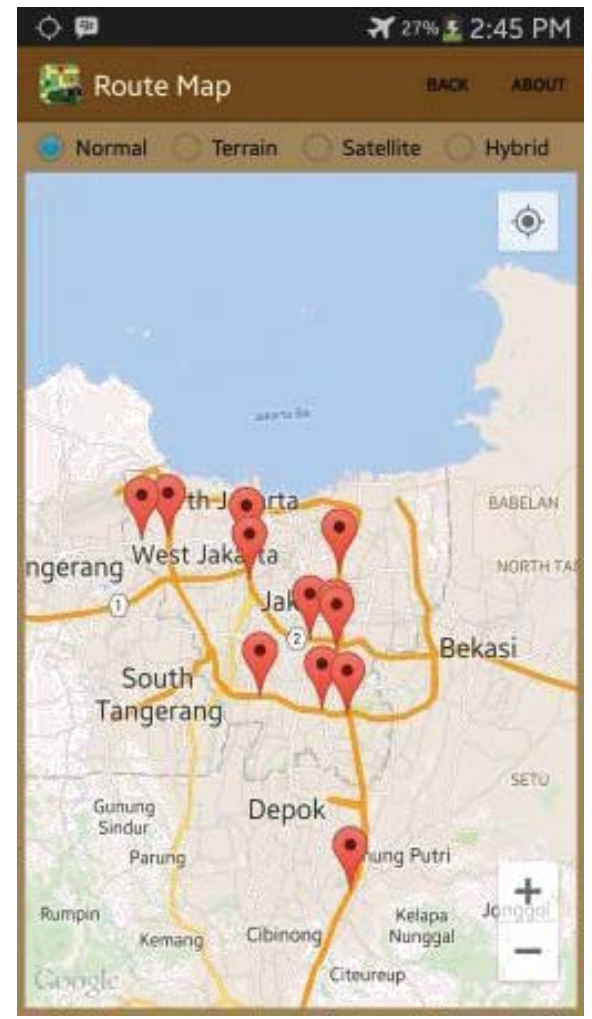

Gambar 9. Tampilan lokasi pada peta

Tabel 1 menunjukkan hasil pencarian informasi bus yang dilakukan dengan menggunakan algoritma Knuth-Morris-Pratt pada aplikasi ini. Beberapa pencarian pada aplikasi ini tidak menemukan hasil karena melibatkan lebih dari dua bus, sedangkan aplikasi ini masih terbatas pada dua bus untuk sekali perjalanan.

Tabel 1.

Hasil pencarian dengan algoritma KMP

\begin{tabular}{|c|c|c|c|}
\hline Lokasi Asal & $\begin{array}{l}\text { Lokasi } \\
\text { Tujuan }\end{array}$ & $\begin{array}{c}\text { Hasil } \\
\text { Pencarian } \\
\end{array}$ & $\begin{array}{c}\text { Lokasi } \\
\text { Jembatan }\end{array}$ \\
\hline Angkasa & Diponegoro & (tidak ada hasil) & 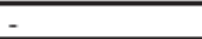 \\
\hline Islamik & Tomang & $\begin{array}{l}\mathrm{AC} 33 \\
\mathrm{AC} 34\end{array}$ & $\begin{array}{l}\text { :One Bus Trip:: } \\
\text { :One Bus Trip:: }\end{array}$ \\
\hline Suprapto & $\begin{array}{l}\text { Terminal } \\
\text { Bekasi }\end{array}$ & $\begin{array}{l}\mathrm{AC} 27 \\
\mathrm{AC} 134+\mathrm{AC} 25 \\
\mathrm{AC} 134+\mathrm{AC} 25 \\
\mathrm{AC} 134+\mathrm{AC} 63 \\
\mathrm{AC} 134+\mathrm{AC} 63 \\
\mathrm{AC} 134+ \\
\mathrm{AC} 132 \\
\mathrm{AC} 134+ \\
\mathrm{AC} 132\end{array}$ & $\begin{array}{l}\text { :One Bus Trip:: } \\
\text { Ahmad Yani } \\
\text { Tol Wiyoto } \\
\text { Wiyono } \\
\text { Ahmad Yani } \\
\text { Tol Wiyoto } \\
\text { Wiyono } \\
\text { Tol Lingkar Luar } \\
\text { TB. Simatupang }\end{array}$ \\
\hline Bambu Apus & Velbak & (tidak ada hasil) & - \\
\hline Slipi & Poris Plawad & $\begin{array}{l}\mathrm{AC} 34 \\
\mathrm{AC} 42 \mathrm{~A}+ \\
\mathrm{AC} 117\end{array}$ & $\begin{array}{l}\because \text { One Bus Trip:: } \\
\text { Tol Jagorawi }\end{array}$ \\
\hline TMII & $\begin{array}{l}\text { Raya } \\
\text { Serpong }\end{array}$ & $\mathrm{AC} 117$ & ::One Bus Trip:: \\
\hline
\end{tabular}




\subsection{Pengumpulan Sampel Data}

Pada penelitian ini, teknik penentuan sampelnya menggunakan non-random sample, yaitu dengan cara sampling purposive, yang mana respondennya dipilih berdasarkan pertimbangan tertentu. Pertimbangannya adalah responden sering atau paling tidak pernah melakukan perjalanan dengan menggunakan angkutan umum, terutama bus Mayasari Bakti yang menjadi studi kasus pada penelitian ini agar dapat menilai keakuratan hasil pencarian dari aplikasi ini. Pengumpulan sampel data diperlukan untuk melakukan analisis mengenai tingkat keberhasilan aplikasi dalam menyediakan informasi melalui tingkat kepuasan pengguna.

Menurut Sugiyono (2012), untuk penentuan sampel berdasarkan jumlah populasi yang tidak diketahui secara pasti membutuhkan jumlah sampel antara 30 dan 500. Sampel data pada penelitian ini diperoleh dengan cara membagikan kuesioner penelitian kepada 40 responden yang telah mencoba menggunakan aplikasi terlebih dahulu. Pemilihan variabel secara garis besar sama dengan variabel pertanyaan mengenai tingkat kepuasan pelanggan pada umumnya sesuai literatur Ives dkk. (1983).

\subsection{Analisis Sampel Data}

Pada setiap lembar kuesioner, terdapat 10 pertanyaan yang menyangkut teknis dan desain. Pertanyaan pertama menyangkut tata letak atribut sistem, seperti button, text view, spinner, list view, hingga radio button, sedangkan pertanyaan kedua mengenai keseluruhan pewarnaan, baik warna tema maupun tulisan, kemudian diikuti dengan pertanyaan mengenai kecepatan dan keakuratan pencarian, kejelasan informasi, dan kegunaan peta pada aplikasi.

Tabel 2 menyajikan hasil perolehan dari 40 kuesioner yang telah diisi oleh responden setelah mencoba aplikasi hasil penelitian ini, yang mana SB untuk sangat baik, B untuk baik, C untuk cukup, K untuk kurang, serta SK untuk sangat kurang.

Untuk mengetahui intervalnya, maka nilai maksimal persentase yaitu 100 dibagi jumlah tingkatan skala, yaitu lima. Perhitungan tersebut membuahkan hasil angka 20, sehingga interval yang digunakan, seperti berikut:

1) Sangat kurang = Angka $0 \%-19,99 \%$

2) Kurang = Angka 20\% - 39,99\%

3) Cukup $=$ Angka 40\% - 59,99\%

4) Baik = Angka $60 \%-79,99 \%$

5) Sangat Baik $=$ Angka $80 \%-100 \%$

Tabel 2.

Hasil perolehan sampel data

\begin{tabular}{|l|c|c|c|c|c|c|}
\hline Kriteria Penilaian & SB & B & C & K & SK & Total \\
\hline Tata letak atribut aplikasi & 15 & 24 & 1 & - & - & $87 \%$ \\
\hline Pemilihan wama tampilan & 8 & 19 & 11 & 2 & - & $\begin{array}{c}76.5 \\
\%\end{array}$ \\
\hline Kecepatan pencarian & 27 & 11 & 2 & - & - & $\begin{array}{c}92.5 \\
\%\end{array}$ \\
\hline $\begin{array}{l}\text { Keakuratan informasi } \\
\text { pencarian }\end{array}$ & 14 & 25 & 1 & - & - & $\begin{array}{c}86.5 \\
\%\end{array}$ \\
\hline $\begin{array}{l}\text { Kejelasan penyampaian } \\
\text { informasi }\end{array}$ & 12 & 20 & 8 & - & - & $82 \%$ \\
\hline $\begin{array}{l}\text { Kegumaan filter lokasi } \\
\text { switch }\end{array}$ & 15 & 19 & 6 & - & - & $82 \%$ \\
\hline $\begin{array}{l}\text { Kegunaan berbagai model } \\
\text { peta }\end{array}$ & 15 & 17 & 4 & 4 & - & $\begin{array}{c}81.5 \\
\%\end{array}$ \\
\hline $\begin{array}{l}\text { Kegumaan penanda pada } \\
\text { peta }\end{array}$ & 11 & 16 & 6 & 5 & 2 & $\begin{array}{c}74.5 \\
\%\end{array}$ \\
\hline $\begin{array}{l}\text { Kemudahan penggunaan } \\
\text { aplikasi }\end{array}$ & 17 & 19 & 4 & - & - & $\begin{array}{c}86.5 \\
\%\end{array}$ \\
\hline
\end{tabular}

Dari hasil kuesioner, diketahui bahwa kecepatan pencarian informasi rute bus melalui aplikasi dengan memanfaatkan algoritma Knuth-Morris-Pratt sangat baik, dengan nilai dari responden sebesar 92.5\%. Keakuratan hasil pencarian dan kejelasan informasi yang 
ditampilkan juga tergolong dalam kategori sangat baik, dengan nilai masing-masing sebesar $86.5 \%$ dan $82 \%$. Sementara itu, dari sisi desain, responden menganggap bahwa tata letak atribut aplikasi sudah sangat baik dengan nilai $87 \%$, namun untuk pemilihan warna tampilan aplikasi masih berada di kategori baik dengan nilai $76.5 \%$. Untuk fitur tambahan yang diterapkan dalam aplikasi, seperti fitur model dan penanda pada peta serta fitur filter lokasi memiliki jangkauan kategori antara baik hingga sangat baik.

\section{Kesimpulan dan Saran}

\subsection{Kesimpulan}

Perancangan dan pembangunan aplikasi informasi rute bus Mayasari Bakti berbasis sistem operasi Android menggunakan algoritma Knuth-Morris-Pratt berhasil dibangun untuk melakukan pencarian bus berdasarkan lokasi asal dan lokasi tujuan yang dipilih user. Berdasarkan analisis data hasil kuesioner dan wawancara dengan responden, aplikasi ini dapat membantu para pengguna angkutan umum yang mengalami kesulitan dalam mencari informasi rute bus Mayasari Bakti.

Kecepatan algoritma Knuth-Morris-Pratt yang digunakan pada aplikasi untuk mengerjakan proses pencarian dinilai sangat baik oleh responden, walaupun hal tersebut masih belum diimbangi dengan perancangan desain yang baik, seperti masalah latar belakang, bahasa, ukuran huruf, dan warna tema.

\subsection{Saran}

Berikut beberapa saran untuk pengembangan aplikasi ini berdasarkan analisa data yang diperoleh dari hasil kuesioner yang telah diisi oleh para responden:

1) Pada aplikasi ini, cakupan angkutan umum masih terbatas pada bus Mayasari Bakti dan kota Jakarta saja, akan menjadi sangat baik jika cakupan moda transportasi dan areanya diperluas.

2) Mengingat luasnya kota Jakarta dan cakupan transportasi yang tersedia, aplikasi ini masih sangat terbatas karena hanya mencakup dua bus. Untuk pengembangannya, cakupan bus dapat diperbanyak agar dapat menyediakan informasi yang lebih maksimal.

3) Saat ini fitur yang tersedia pada peta masih terbatas pada penanda lokasi-lokasi dari rute saja, dan reponden mengharapkan kedepannya selain menunjukkan lokasi, peta juga dapat menunjukkan rute, estimasi waktu dan jarak yang ditempuh dari hasil pencarian yang dipilih user.

4) Aplikasi ini masih lebih terfokus ke penggunaan algoritma Knuth-Morris-Pratt daripada desain, sehingga beberapa pewarnaan tampilan dan ukuran huruf dinilai kurang tepat. Hal ini dapat lebih diperhatikan, bila perlu dapat berkonsultasi atau bahkan mengajak desainer grafis untuk pengembangannya.

5) Faktanya tidak semua orang Indonesia dapat berbahasa Inggris, namun pihak PT Mayasari Bakti juga menginginkan aplikasi dalam bahasa Inggris mengingat akan dimulainya pasar bebas ASEAN (MEA), sehingga untuk pengembangannya, aplikasi ini dapat dibuat dalam Bahasa Indonesia dan Bahasa Inggris.

6) Pembaharuan informasi pada aplikasi ini masih dilakukan secara manual dengan melakukan perubahan pada file system, untuk pengembangannya agar update informasi dapat dilakukan dengan mudah, maka halaman admin dapat ditambahkan.

7) Google Maps API menyediakan banyak jenis peta untuk digunakan para pengembang, namun tidak perlu semua fitur yang disediakan diterapkan pada aplikasi. Ada baiknya fitur-fitur tambahan yang ingin diimplementasikan pada aplikasi dapat dipertimbangkan lebih dalam terlebih dahulu.

\section{Daftar Pustaka}

Agus, P. 2010. DPRD: Tarif Busway Belum Pantas Naik [online]. Tersedia dalam: http://m.inilah.com/news/detail/ 262771/dprd-tarif-busway-belum-pantas-naik [diakses 23 Desember 2014].

Andika, D. 2012. Implementasi Algoritma Knutt-Morris-Pratt untuk Perancangan Game Interaktif”. Fakultas Ilmu Komputer Universitas Pembangunan Nasional Veteran, Jakarta.

Android Developers. Tanpa tahun. Get The Android SDK [online]. Tersedia dalam: http://developer.android.com/sdk/ index.html [diakses 30 April 2014].

Bhawiyuga, A., Mazharudin Shiddiqi, A., dan Adipratomo, B. 2011. Sistem Pelaporan dan Informasi Posisi 
Kereta Api Berbasis Global Positioning System (GPS) pada Device Berbasis Android. Fakultas Teknologi Informasi Institut Teknologi Sepuluh November, Surabaya.

Dinas Komunikasi, Informatika, dan Kehumasan Pemprov DKI Jakarta. Tanpa tahun. Info Transportasi [online]. Tersedia dalam: http://www.jakarta.go.id/web/bus [diakses 30 April 2014].

Elian, A., Shiddiqi, A.M., dan Studiawan, H. 2012. Layanan Informasi Kereta Api Menggunakan GPS, Google Maps, dan Android. Fakultas Teknologi Informasi Institut Teknologi Sepuluh November, Surabaya.

Emmanuel, A.W.R. dan Salim, A. 2013. Pembuatan Sistem Pelayanan Taksi dengan Menggunakan Android Google Maps dan Ruby on Rails. Fakultas Teknologi Informasi Universitas Kristen Maranatha, Bandung.

Fuaduddin, M.F., Aini, Q., dan La Katjong, B. 2012. Aplikasi Informasi Trayek Angkutan Umum Berbasis Mobile. Fakultas Sains dan Teknologi Universitas Islam Negeri Syarif Hidayatullah, Jakarta.

Harahap, R.H. 2011. Skala Likert [online]. Tersedia dalam: http:// www.scribd.com/doc/69516622/SkalaLikert\#scribd [diakses 27 Desember 2014]

Google Developers. 2014. Map Objects [online]. Tersedia dalam: https://developers.google.com/maps/documentation/ android/map [diakses 5 Desember 2014].

Indriany. Tanpa tahun. Informasi Rute / Trayek / Jalur Angkutan Umum Bus Mayasari Bakti di Jakarta [online]. Tersedia dalam: http://www.indriany.com/informasi-rute- trayek-jalur-angkutan-umum-bus-mayasaribakti-di-jakarta/ [diakses 9 September 2014].

Ives, B., Olson, M.H., dan Baroudi, J.J. 1983. The Measurement of User Information Satisfaction. Communications of the ACM, New York.

Kotler, P. 2003. Marketing Management. Edisi 9. Prentice-Hall, New Jersey.

Lindung, Y.D. 2012. Implementasi Android SDK dalam Pembuatan Aplikasi Mobile "Kalkulator MIPA" untuk Sekolah Menengah Pertama. Fakultas Teknik Informatika Sekolah Tinggi Manajemen Informatika dan Komputer AMIKOM, Yogyakarta.

Mathew, G. 2013. Google Map Android API v2 - Switching between Normal View, Satellite View and Terrain View [online]. Tersedia dalam: http://wptrafficanalyzer.in/blog/ google-map-android-api-v2-switching-bet ween-normal-view-satellite-view-and-terrain-view/ [diakses 25 November 2014].

Naufal, H.H. 2014. Menampilkan Lokasi Pengguna di Peta Menggunakan Android Maps API v2 [online]. Tersedia dalam: http:/www.twoh.co/2014/ 02/menampilkan-lokasi-pengguna-di-peta-menggunakan-android-mapsapi -v2/ [diakses 23 November 2014].

Sugiyono. 2012. Metode Penelitian Kuantitatif, Kualitatif, dan R\&D. Alfabeta, Bandung.

Yusup, S.M. 2010. Implementasi Algoritma KMP dan Boyer-Moore dalam Aplikasi Search Engine Sederhana. Sekolah Teknik Elektro dan Informatika Institut Teknologi Bandung, Jakarta.

Zulkifli, A. 2014. Diwawancarai oleh penulis. Jakarta, Indonesia, 8 Desember. 